\section{Mercury in North-Eastern Atlantic Ocean Water}

FEW measurements have been made of the concentration of mercury in sea water and there are considerable differences in the values reported. High values of 1.6 to $3.6 \mu \mathrm{g}$ total $\mathrm{Hg} / \mathrm{l}$. for oxidized samples from Minamata Bay, Japan ${ }^{1}$, probably reflect the serious pollution of that $\mathrm{area}^{2}$. Ocean water from the north-western Pacific has been reported ${ }^{3}$ to contain from 0.06 to $0.27 \mu \mathrm{g} / 1$., with the highest concentrations in deep water. These measurements were made spectrophotometrically with dithizone, which was also used, in different conditions following anion exchange concentration, in the analysis of waters from the Solent and the English Channel ${ }^{4}$. These were found to contain lower amounts of mercury, from 0.014 to $0.021 \mu \mathrm{g} / \mathrm{l}$., which are quite similar to that $(0.03 \mu \mathrm{g} / \mathrm{l}$.) found for a single sample from off Heligoland in the early work

\begin{tabular}{|c|c|c|c|}
\hline \multicolumn{4}{|c|}{ Table 1 Mercury in Water Samples } \\
\hline $\begin{array}{l}\text { Discovery } \\
\text { station } \\
\text { No. }\end{array}$ & Position & $\underset{(\mathrm{m})}{\text { Depth }}$ & $\underset{(\mu \mathrm{g} / \mathrm{L} .)}{\text { Mercury }}$ \\
\hline 7555 & $47^{\circ} 22^{\prime} \mathrm{N} 7^{\circ} 38^{\prime} \mathrm{W}$ & about 1,000 & $\begin{array}{l}0.006 \\
0.020\end{array}$ \\
\hline 7556 & $\begin{array}{l}46^{\circ} 35^{\prime} \mathrm{N} 8^{\circ} 28^{\prime} \mathrm{W} \\
\text { (bottom at } 4,743 \mathrm{~m} \text { ) }\end{array}$ & about $\begin{array}{r}1,000 \\
4,665\end{array}$ & $\begin{array}{r}0.015 \\
0.013 \\
<0.003\end{array}$ \\
\hline 7560 & $\begin{array}{l}47^{\circ} 22^{\prime} \mathrm{N} 7^{\circ} 37^{\prime} \mathrm{W} \\
\text { (bottom at } 3,858 \mathrm{~m} \text { ) }\end{array}$ & $\begin{array}{l}4,003 \\
3,506\end{array}$ & 0.015 \\
\hline $\begin{array}{l}7602 \\
7604\end{array}$ & $\begin{array}{l}44^{\circ} 47^{\prime} \mathrm{N} 9^{\circ} 10^{\prime} \mathrm{W} \\
40^{\circ} 42^{\prime} \mathrm{N} 9^{\circ} 31^{\prime} \mathrm{W}\end{array}$ & $\begin{array}{l}0 \\
0\end{array}$ & $\begin{array}{l}0.017 \\
0.018\end{array}$ \\
\hline 7605 & $39^{\circ} 32^{\prime} \mathrm{N} 9^{\circ} 35^{\prime} \mathrm{W}$ & 0 & 0.013 \\
\hline
\end{tabular}

* There is uncertainty about the operation of the two sampling bottles which tripped at 2,000-2,200 m. Either one or both of the bottles may have sampled at that depth or at $3,700 \mathrm{~m}$.

These data represent a situation, not unusual in analytical marine geochemistry, where interpretation is difficult not just because there are only a few results for widely separated areas but also because the differences may reflect analytical effects as well as real regional variations. In view of the increasing interest in the marine distribution of mercury, related to its local importance as a pollutant, more information is needed. The results are given here for analyses of ocean water samples from the north-eastern Atlantic, collected in late February and early March 1971 . Surface samples $(30$ 1.) were taken with a plastic bucket and subsurface samples $(151$.) with polypropylene water bottles. They were stored in polyethylene bottles after acidification to $0.1 \mathrm{~N}$ with purified hydrochloric acid and addition of ${ }^{203} \mathrm{Hg}$ as an isotopic dilution tracer. Analysis was carried out by the above-mentioned procedure which has been outlined in more detail before ${ }^{4}$ and which recovers dissolved mercury present either in inorganic forms or as methylmercury. The samples were not filtered; they contained little particulate material and previous work ${ }^{5}$ has shown that this would contribute negligibly to the measured mercury.

The results are given in Table 1 . The concentrations in the four surface samples were between 0.013 and $0.018 \mu \mathrm{g} / \mathrm{l}$; those in three deep water samples were closely similar but two other deep samples showed markedly lower concentrations.

T. M. LEATHERLAND

J. D. Burton

Department of Oceanography,

University of Southampton

M. J. MCCARTNEY

F. CULKIN of Stock and Cucuel 5 .

1 Hosohara, K., Kozuma, H., Hawasaki, K., and Tsuruta, T., J. Chem. Soc. Japan, Pure Chem. Sect., 82, 1479 (1961).

${ }^{2}$ Kurland, T. L., Faro, S. N., and Siedler, H., Wld Neurol., 1, 370 (1960).

${ }^{3}$ Hosohara, K., J. Chem. Soc. Japan, Pure Chem. Sect., 82, 1107 (1961).

4 Burton, J. D., and Leatherland, T. M., Nature (in the press).

5 Stock, A., and Cucuel, F., Naturwissenschaften, 22, 390 (1934).

\section{Accelerated Rates of Rainfall}

RAINFALL intensity within clouds may be greatly increased by the production of satellite drops when raindrops collide, and this process could explain the extremely high rates of rainfall development reported in certain clouds ${ }^{1,2}$. We have set out to test this possibility by laboratory experiments.

Two streams of uniformly sized drops, of radii $R$ and $r$, were made to collide while falling through air with a relative velocity $U$. Photographs were taken of the collision events over a wide range of values of $R, r, U$ and the collision parameter $X$ which is the perpendicular distance from the centre of one drop to the trajectory of the centre of the other. In general it was found that for low velocity central collisions the drops coalesced permanently but that for higher velocity collisions at larger values of $X / R+r$ the drops temporarily coalesced but then rotated and separated, usually drawing out a thin filament of water, several drop diameters in length, which condensed to form a small number of satellite drops (Fig. 1). Calculations based on the assumption that the drops will separate if their rotational energy exceeds the surface energy required to form two drops of the original size predict a critical threshold for separation given by the equation

$$
\frac{r \rho U^{2}}{\sigma}\left(\frac{X}{R+r}\right)^{2}=3.2 \gamma(R / r)
$$

where $\rho$ is the density and $\sigma$ the surface tension of water and $\gamma(R / r)$ is a function which varies from 1 for $R=r$ to 2.9 for $R=3 r$. Excellent agreement with this equation was found experimentally. The average number of satellite drops produced when separation occurred was three, but it varied from one to about eight. This was found to be fairly insensitive to quite wide variations in $U, R, r$ and $X /(R+r)$. The average radius of the satellites is seen from Fig. 2 to be about $80 \mu \mathrm{m}$, corresponding to a raindrop with terminal velocity of $\sim 0.6 \mathrm{~ms}^{-1}$.

If raindrops falling through clouds suffer such collisions the rate of transformation of cloud water to rainwater will be

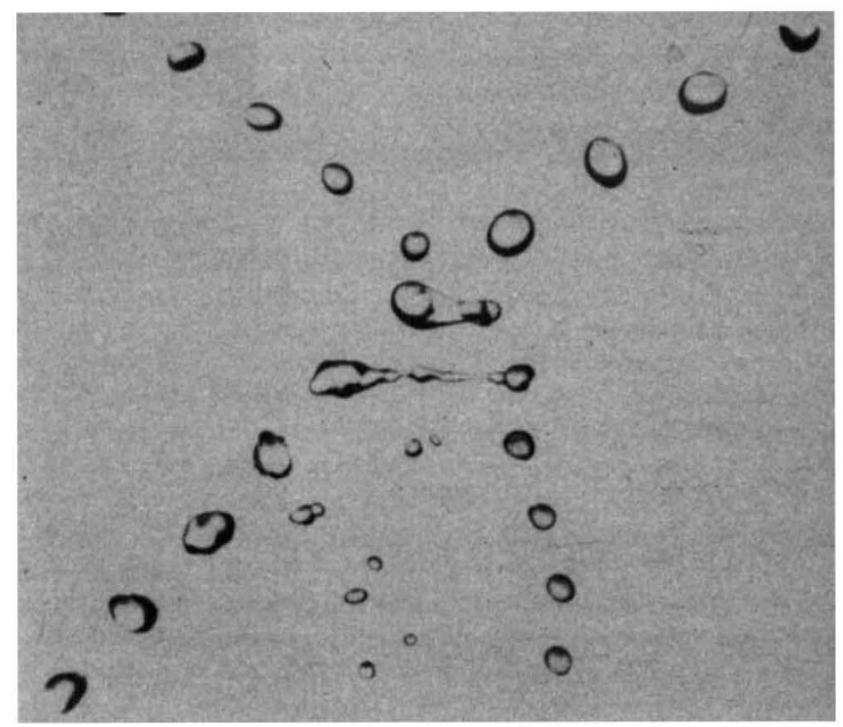

National Institute of Oceanography, Wormley, Godalming, Surrey

Fig. 1 Two water drops of radii 510 and $340 \mu \mathrm{m}$ colliding in air and separating to form satellite drops.

Received June 1, 1971. 